know about their contemporary, Maurice Hilleman, a researcher who developed more than 30 vaccines (including those for measles, mumps, and chickenpox) and who is credited with saving more lives than any other 20thcentury scientist.

When people benefit from public health measures, they often don't recognize that they have been helped. In the United States today, it is easy for people to take it for granted when, on any particular day, they don't get sick at work (because of airquality improvements), aren't poisoned (because the food is safe), or don't get run over (because the walkway has been separated from the road). In the few cases in which people do recognize that they've been helped by preventive measures, they rarely know who provided the benefit. In contrast, the help provided by curative physicians is more easily identified. So whereas grateful patients, in turn, provide much financial support for hospitals, there is generally no grateful public providing substantial support for public health initiatives.

Fourth, some public health efforts encounter not just disinterest but out-and-out opposition. Such initiatives often require societal change, which runs counter to the well-documented human characteristics of "status quo bias" and "tradition-bound resistance." Even the most successful public health initiatives, such as the "great sanitary awakening" of the 19th century, which dramatically reduced the spread of tuberculosis, were met with fierce opposition. ${ }^{4}$

Societal change is hard, and it is especially difficult when it imposes costs on powerful special interests. In the past halfcentury, those opposing beneficial public health measures have included some of our most potent political lobbies, representing the interests of the alcohol, tobacco, firearm, automobile, coal, and oil industries. For instance, Americans who die before 40 years of age are more likely to be killed by an injury than a disease. In the early 1990s, firearms were the second-leading cause of injury-related death in the United States, killing 100 civilians per day. The Centers for Disease Control and Prevention (CDC) began spending a disproportionately small amount of money on this enormous issue $-\$ 2.6$ million (about a penny per person) on data collection and research each year. One CDC-funded study of violent deaths in the home showed that the presence of a gun in the household was a risk factor for such deaths. ${ }^{5}$ But congressional delegates on the CDC appropriations committee, bowing to the wishes of an outraged gun lobby, tried to shut down firearm-related activities at the CDC. Although initially unsuccessful, their attempt had such a chilling effect that the CDC has effectively stopped funding research on this major public health problem.

In contrast, increases in resources for medical care are usually promoted rather than opposed by large special interests, from pharmaceutical and medical insurance companies to physicians, nursing homes, and hospitals.

Epidemiologists are taught to recognize and address the problems of systematic error. Hospitals are learning to detect and prevent systematic errors in providing medications and other practices. Similarly, our country needs to understand and try to correct systematic policy errors including the tendency to underinvest in public health.

Disclosure forms provided by the author are available with the full text of this article at NEJM.org.

From the Harvard Injury Control Research Center, Harvard School of Public Health, Boston.

1. McClure SM, Laibson DI, Loewenstein G, Cohen JD. Separate neural systems value immediate and delayed monetary rewards. Science 2004;306:503-7.

2. Small DA, Loewenstein G. Helping a victim or helping the victim: altruism and identifiability. J Risk Uncertain 2003;26:5-16.

3. Evans RG, Barer ML, Marmor TR, eds. Why are some people healthy and others not? The determinants of health of populations. New York: Aldine de Gruyter, 1994.

4. Winslow CEA. The evolution and significance of the modern public health campaign. New Haven, CT: Yale University Press, 1923.

5. Kellermann AL, Rivara FP, Rushforth SB, et al. Gun ownership as a risk factor for homicide in the home. N Engl J Med 1993;329: 1084-91. [Erratum, N Engl] Med 1998;339: 928-9.]

Copyright (๑) 2010 Massachusetts Medical Society.

\title{
Syphilis and Social Upheaval in China
}

Joseph D. Tucker, M.D., Xiang-Sheng Chen, M.D., Ph.D., and Rosanna W. Peeling, Ph.D.

Cyphilis, a sexually transmitted $\checkmark$ infection (STI) that was nearly eliminated from China 50 years ago, ${ }^{1}$ is now the most commonly reported communicable disease in Shanghai, China's largest city. ${ }^{2}$
No other country has seen such a precipitous increase in reported syphilis cases in the penicillin era. 
In 2008, an average of more than 1 baby per hour was born with congenital syphilis in China, for a total of 9480 cases; the rate had increased by a factor of 12 during the previous 5 years (see graph). A disease with social roots, syphilis has become a major scourge lurking in the shadows of a country that has rapidly ascended to the status of a global economic powerhouse.

Although syphilis infection may be asymptomatic and difficult to diagnose without widespread screening, the public health impact of the disease is all too clear. People with syphilis have an increased risk of acquiring and transmitting human immunodeficiency virus (HIV) infection; more than half of pregnant women with syphilis have a spontaneous abortion or stillbirth; and babies with congenital syphilis may have serious, irreversible sequelae with rates of death in infancy of more than $50 \% .^{3}$

The recent expansion of the Chinese syphilis epidemic holds important lessons about social and environmental influences on sexual health, and these lessons have corollaries for other countries and cultures. But in China, the breadth and depth of social change during the past two decades have far exceeded the incremental urbanization and development seen in other low- and middle-income countries. Just as past major social upheavals, including world wars, have been associated with an increased rate of STIs, contemporary social factors have an effect on both the spread and control of syphilis. After China's economy became increasingly market-based in the 1980 s, the growing numbers of Chinese businessmen with money and young women without money translated into expanded demand and supply for the country's commercial sex industry. Meanwhile, Chinese social structures influence the effectiveness of syphilis-control programs in two important but countervailing ways: although newly established advocacy organizations for marginalized groups provide a foundation for expanding such programs, the social stigma associated with high-risk behaviors is a powerful deterrent to widespread syphilis-screening efforts.

The behaviors that confer the highest risk of syphilis - selling or buying sex and male homosexual sex - elicit formal and informal condemnation from Chinese society. National surveillance data reveal that female sex workers and men who have sex with men disproportionately bear the burden of the Chinese syphilis epidemic, in part because unsafe sexual practices in these populations are driving the rate of infection ${ }^{2}$ and in part because the stigma attached to their sexual behaviors discourages them from obtaining needed care. In China, at least one third of men who have sex with men are married, and the transmission of syphilis to their wives and then children is an important consideration. The limited data that are available suggest that fear of being identified as a "social deviant" may steer members of marginalized groups away from official STI clinics where licensed physicians use national guidelines and have standardized laboratory facilities.

Empirical data suggest that there is good reason for Chinese sex workers in particular to fear public authorities, since the police's traditional response to com- mercial sex work has ranged from fines to administrative detention in "reeducation centers." ${ }^{4}$ Recently, there has been increased collaboration between public health and public security departments to expand STI and HIV services among detained sex workers, but there are still important social consequences for sex workers who are detained. ${ }^{4}$ Although the stigma associated with syphilis and other STIs is present the world over, its burden can be particularly severe in a social structure such as China's, which highly values dignity or "face" (mianzi) and social relationships (guanxi). Stigma and the isolation to which it can lead present barriers to widespread syphilis screening among high-risk groups in China.

How to systematically provide programs for syphilis testing and control for stigmatized high-risk groups in China is a major public health issue today, especially given that a "civil society" - the realm of nongovernmental organizations, associations, and corporate bodies that can take collective action for the common good - is only beginning to emerge there. The conventional public health approach focusing on empowering marginalized groups assumes the presence of a vibrant civil society, and several local advocacy organizations have stepped in to fill this important niche. These budding organizations help to provide counseling and syphilis testing to marginalized populations, and their approach has already been replicated in many regions of China that have a high burden of syphilis infection. ${ }^{5}$

Providing syphilis testing in nontraditional sites is possible with the use of rapid syphilis tests 


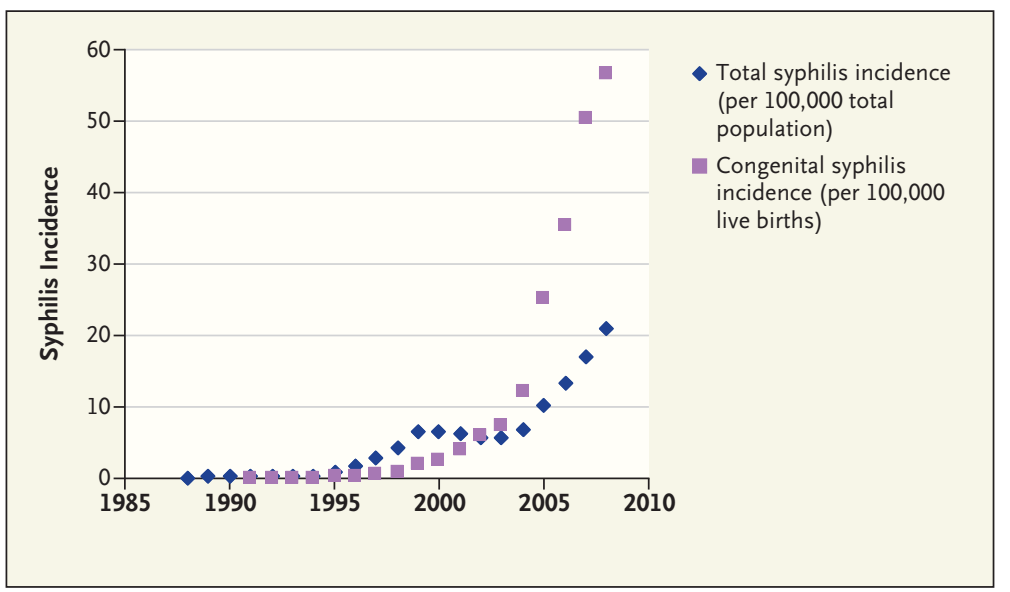

Reported Overall Incidence of Syphilis per 100,000 Population and Incidence of Congenital Syphilis per 100,000 Live Births in China.

Data are from the National Center for STD Control in Nanjing, China.

that are sensitive and specific and can use finger-prick blood. These simple, inexpensive tests do not require any equipment, and results are available within 30 minutes. ${ }^{5}$ The rapid test can be used at remote clinics that cannot perform traditional syphilis tests and also on site at saunas, brothels, entertainment venues, and other commercial sex venues. Rapid tests are helping to expand syphilis screening in many geographic areas where screening was not possible before, and they provide the impetus for people with syphilis to be linked to treatment and partner-referral programs. Now that some advocacy organizations have built up a track record of identifying and responding to local syphilis epidemics, systematic ways of sustaining these efforts and linking them to HIV programs are needed.

Despite the growing voice of local advocacy organizations, scaling up successful syphilis-control projects or initiatives for marginalized groups is a complex pro- cess. Fostering sustainable syphilis-control programs demands social changes of great magnitude. In 1936, Surgeon General Thomas Parran launched a nationwide program in the United States to diagnose and treat syphilis, placing syphilis control front and center on the national public health agenda. Syphilis was thereby transformed from a sinful predicament to a disease worthy of targeted public health efforts - an important transition that catalyzed the expansion of local public health resources.

Such boons to syphilis control have a history in China as well and are a major reason why syphilis became so uncommon 50 years ago. During the early 1950s, Ma Haide (the American physician George Hatem, who had become a Chinese citizen) and other top Chinese public health leaders formed interdisciplinary committees to help close down the commercial sex industry. Within several weeks after this decision was reached, hun- dreds of brothels had been permanently shut down, thousands of sex workers were being treated with penicillin, and syphilis control became routine among former sex workers. One decade after these sweeping changes took place, STIs were virtually unknown in China. Although similar massive changes are unlikely to be feasible in modern China, the essential elements of this approach should be reviewed: largescale normalization of syphilis testing and treatment, interdisciplinary cooperation, and a deep level of commitment and support at the highest levels of government.

As the numbers of syphilis cases continue to soar in many regions of China, the public health mandate for substantial change has been strengthened. Free screening and treatment for pregnant women and high-risk groups are being offered in the province with the highest burden of disease. The Chinese government currently has an ongoing project that analyzes the impact of expanded STI care on the rate of new HIV infections. Government programs have already laid the foundation for change by helping to introduce syphilis testing at nontraditional sites and allowing the development of advocacy organizations and support groups. But broader recognition of STIs as a public health problem, renewed financial commitment from the government, and technical input from advocacy organizations are imperative if syphilis is to be controlled and eliminated once again.

\footnotetext{
Disclosure forms provided by the authors are available with the full text of this article at NEJM.org.
} 
From the Department of Medicine, Massachusetts General Hospital, Boston, and the Department of Medicine, University of North Carolina at Chapel Hill, Chapel Hill (J.D.T.); the Department of Epidemiology, National Center for STD Control, Chinese Academy of Medical Sciences and Peking Union Medical College Institute of Derma tology, Nanjing, China (X.-S.C.); and the Clinical Research Unit, London School of Hygiene and Tropical Medicine, London (R.W.P.).
1. Cohen MS, Henderson GE, Aiello P, Zheng $\mathrm{H}$. Successful eradication of sexually transmitted diseases in the People's Republic of China: implications for the 2lst century. J Infect Dis 1996;174:Suppl 2:S223-S229.

2. Chen ZQ, Zhang GC, Gong XD, et al. Syphilis in China: results of a national surveillance programme. Lancet 2007;369:1328

3. Holmes K, Sparling P, Stamm W, et al. Sexually transmitted diseases. 4 th ed. New York: McGraw-Hill Medical, 2008.
4. Tucker J, Ren X, Sapio F. Incarcerated sex workers in China: social suffering and social justice countermeasures. Soc Sci Med 2010;70:121-9.

5. Tucker JD, Hawkes SJ, Yin YP, et al. Scaling up syphilis testing in China: implementation beyond the clinic. Bull World Health Organ (in press).

Copyright (C) 2010 Massachusetts Medical Society. 